\title{
Editorial
}

\section{Health Reform: What have we learned and were to next!}

Recently I was talking to a colleague of mine from Hong Kong and he reminded me that Hong Kong had had 28 years of health reform. A period just slightly longer than we had known each other. We are deeply imbued in the management and organisation of health services and health systems and, therefore public health policy. He suggested that there should be a lot of learning for us all from that period and, he was exploring how that might happen. I agreed with the idea and the need to think it through. I also recognised potential for the Journal to play some role in that suggestion. Most national health systems have undergone extensive reform so there should be a lot of learning for all of us from that reform.

The discussion is at a time when Honk Kong has released a health system research report titled 'Fit for Purpose: A health System for the 21st Century - Research Report' published by the 'Our Hong Kong Foundation'. [1] I was drawn to this Report substantially as a result of the above discussions, secondly because of my contact and familiarity with the Hong Kong health system and because it does not take long, only a few pages, before you appreciate that the central theme of the Report is a proposed transformation and focus on primary healthcare (PHC) for Hong Kong. Not only that, it is replete with international context, frameworks, models and case studies around this topic. It adds newer language of health reform for us to consider, something of interest to the author of this editorial. [2] The Report context is sufficiently broad for it to be relevant in a range of national health systems. I commend the document to you for more detailed reading and reference.

In addressing the need to transform PHC the Report states that we need to change the health system to be 'fit for purpose'. The challenge is, can the system meet its intended purpose? It refers to changing contexts, needs, knowledge and technologies. It talks of transforming to primary care - led integrated care. [1, p.3] The Report talks about supporting 'all of our citizens over their life course' [1, p.4], re-orientating the health system for the "community of persons" $[1, p .5]$ and a system where 'patients are facilitated to take ownership over their own health'. [1, p.5]

The Hong Kong health system, like many others are addressing the challenge of fragmentation in health systems, unbalanced and segmented provision, inadequate medical-social collaboration and community care. Themes explicit in the qualitative data of the Report are that healthcare is not keeping pace with changing needs and this is when the science, technology, diagnostics, communication and service models enables services to be more accessible in communities. A further theme was the critical aspects of financing, funding and payment systems as critical tools to facilitate systems operation, reduce barriers and improve governance. [1. P,53-71] Another suggestion that piqued my interest was the suggestion that primary care-led integrated person-centred models of service delivery be organised around primary care hubs nested within community networks'. I think both virtual and as entities. Again, this editor is a supporter of networks of practice as an approach to cross sectorial boundaries and to bring service providers and access to services together.

The Hong Kong health system, despite some of the Report content is well regarded and this venture into $\mathrm{PHC}$ led reform is consistent with some of the positivity about that system and consistent with international trends. One of the key authors is Professor Eng Kiong Yeoh, GBS, OBE, JP who is currently Professor of 


\section{Asia-Pacific Journal of Health Management

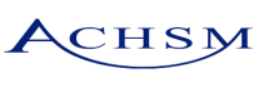

Public Health, Director at the JC School of Public Health and Primary Care of The Chinese University of Hong Kong and Head of Division of Health System, Policy and Management. He was the first Chief Executive of Hong Kong Hospital Authority and former Secretary for Health, Welfare and Food of the HKSAR Government. Together with colleagues he has presented us with rich data, international content, case studies and the qualitative perceptions of stakeholders. The Report calls for responses and discussions, but the Chief Executive of Hong Kong Carrie Lam is already moving in the direction of the Reports key recommendations and is committed to enhancing district-based primary healthcare services.

No doubt there will be interesting debates about the proposals within Hong Kong. However, the concept of district health services is a notable feature of progressive health systems such as that of Thailand where strategy, policy and research is at the national level and service delivery is at the local district level and, increasingly involving cross sectorial approaches. For PHC to be successfully transformed it needs to be underpinned by community engagement and be consistent with theoretical concepts of localism and the principle of subsidiarity. [3]

My challenge to you in writing this editorial is firstly to encourage you to read the Hong Kong Report. Secondly to alert you to the fact that we intend to encourage articles in 2019 that might provide us with reflections and learnings from the history of health reform. Given my interest in the language of health reform I would also suggest that you should delve into that language to add into your writing some of my favourite terms - 'what problem are we attempting to resolve' [4] - whose interests are being served [5] and now are our health systems, services and organisations and are we 'fit for purpose'. [1]

\section{DS Briggs}

\section{Editor}

\section{References}

1. Our Hong Kong Foundation. (2018). Fit for Purpose: A health System for the 21st Century -Research Report. Available from https://www.ourhkfoundation.org.hk/en/ reports $/ 19$

2. Briggs DS Isouard G. The Language of Health Reform and Health Management: critical issues in the management of health systems. Asia Pacific Journal of Health Management. 2016;11(3) Available from

https://www.achsm.org.au/Public/Resour ces/Journal/Public/Resources/Journal/Jou rnal_Home.aspx?hkey=57214087-f86742e2-a0d4-2250e6076385.

3. Briggs DS. Localism: A way forward? Asia Pacific Journal of Health Management. 2014;9(1). Available from https://www.achsm.org.au/Public/Resour ces/Journal/Public/Resources/Journal/Jou rnal_Home.aspx?hkey=57214087-f86742e2-a0d4-2250e6076385

4. Dwyer, JM. 2004, 'Australian health system restructuring - What problem is being solved?' Australian and New Health Policy, Vol. 1, no. 6, pp. 19-31.

5. Alford, R. 1975, Health Care Politics, The University of Chicago Press, Chicago. 